\title{
Treatment with Pluchea indica (L.) Less. leaf ethanol extract alleviates liver injury in multiple low-dose streptozotocin-induced diabetic BALB/c mice
}

\author{
JONGDEE NOPPARAT $^{1}$, AEKKARAJ NUALLA-ONG $^{2,3}$ and AMORNRAT PHONGDARA ${ }^{2,3}$ \\ ${ }^{1}$ Department of Anatomy; ${ }^{2}$ Center for Genomics and Bioinformatics Research; \\ ${ }^{3}$ Faculty of Medical Technology, Prince of Songkla University, Hat Yai, Songkhla 90110, Thailand
}

Received September 19, 2019; Accepted April 6, 2020

DOI: $10.3892 /$ etm.2020.8877

\begin{abstract}
Hyperglycemia-induced oxidative stress and inflammation are hallmarks of liver damage in diabetes mellitus. Accumulating evidence has demonstrated that Pluchea indica leaf ethanol extract (PILE) possesses strong antioxidant and anti-inflammatory properties. However, studies of its effects on liver damage in streptozotocin (STZ)-induced diabetic animals remain insufficient. To the best of our knowledge, the present study was the first to illustrate that PILE mitigated liver injury in STZ animals. Mice were first pretreated with PILE at either $50 \mathrm{mg} / \mathrm{kg}$ (PILE 50) or $100 \mathrm{mg} / \mathrm{kg}$ (PILE 100) 2 weeks prior to the induction of hyperglycemia by multiple low doses of STZ. The mice were then fed with PILE 50 or PILE 100 for 4 or 8 weeks, following which liver weight, pathological changes, oxidative stress parameters, inflammation-related markers and caspase-mediated apoptosis were measured at each time point. Untreated STZ mice exhibited abnormal increases in liver weight and severe pathological changes. However, PILE 100 reduced the severity of the STZ-induced diabetic phenotype at both time points. A significant decrease in the levels of superoxide dismutase and catalase, in addition to an increase in malondialdehyde, were observed in the livers of untreated STZ mice, all of which were significantly reversed by treatment with PILE 100 for 8 weeks. Western blot analysis revealed reduced levels of liver inflammatory markers, including interleukin-6, tumor necrosis factor- $\alpha$, $\mathrm{NF}-\kappa \mathrm{B}$ p65, transforming growth factor- $\beta 1$ and protein kinase $\mathrm{C}$ following PILE 100 treatment. Additionally, changes in the levels of apoptotic markers indicated that PILE 100 significantly attenuated caspase- 9 and -3 expression, whilst preserving that of the $\mathrm{Bcl}-2$ protein. In conclusion, the present
\end{abstract}

Correspondence to: Dr Jongdee Nopparat, Department of Anatomy, Prince of Songkla University, 15 Karnjanavanich Road, Hat Yai, Songkhla 90110, Thailand

E-mail: jongdee.n@psu.ac.th

Key words: pluchea indica, antidiabetic activity, antihyperglycemia, anti-inflammation, antioxidant, diabetes, liver study revealed that PILE alleviates hyperglycemia-induced liver injury by normalizing the various mediators of oxidative stress, inflammation and apoptosis.

\section{Introduction}

Diabetes mellitus (DM) is recognized as a metabolic disorder this is primarily caused by dysregulation in the production, secretion or action of insulin, subsequently resulting in a global life-threatening disease (1). Patient morbidity is closely associated with DM-related complications, which can affect a number of vital organs including the eyes, heart, kidneys and liver $(2,3)$. Statistically, 50-73\% patients with end-stage liver disease are found to be obese and diabetic, where liver damage is a major complication of DM $(3,4)$. Multiple mechanisms of DM-induced liver damage have been identified, in which hyperglycemia is among the predominant causative factors (4-6). Due to sensitivity to glucose homeostasis and insulin, the liver is highly susceptible to hyperglycemia-induced oxidative stress, which activates the inflammatory cascade further (5).

A number of studies have previously highlighted that under hyperglycemic conditions, a reduction in the levels of antioxidants, including superoxide dismutase (SOD) and catalase (CAT), coupled with increased levels of malondialdehyde (MDA), causes an increase in reactive oxygen species (ROS), leading to oxidation-mediated liver damage $(4,5)$. Oxidative stress has also been linked to the activation of $\mathrm{NF}-\kappa \mathrm{B}$ during DM, which may subsequently upregulate the expression of pro-inflammatory cytokines (7). In hepatocytes, hyperglycemia-induced NF- $\kappa \mathrm{B}$ activation is induced by mediators released from Kupffer cells, such as interleukin (IL)-6 and tumor necrosis factor (TNF)- $\alpha$. IL- 6 and TNF- $\alpha$ form a positive feedback loop to further stimulate activated $\mathrm{NF}-\kappa \mathrm{B}$, thereby increasing the infiltration of inflammatory cells to the site of hepatic injury (8). In addition, NF- $\kappa \mathrm{B}$ forms the central link between hepatic inflammation and fibrosis through the upregulation of its downstream inflammatory effectors, namely transforming growth factor (TGF)- $\beta 1$ and protein kinase C (PKC) (9). A combination of these deleterious events aggravates the diabetic liver. In some cases, DM can also cause excessive adipocyte accumulation in the liver, resulting in non-alcoholic fatty liver disease (NAFLD) $(5,10)$. Therefore, 
novel treatment strategies that include the development of naturally occurring antioxidants that resist oxidative stress and those that normalize inflammation, may be of interest in the management of DM-induced liver damage.

The potential of Pluchea indica $(P$. indica) leaves as a traditional herbal medicine is a subject of growing interest in the scientific community. Its uses have been previously documented by various researchers, which include its antioxidant $(11,12)$, anti-inflammatory $(13,14)$ and anti-hyperglycemic (15-17) properties. $P$. indica exerts its antioxidant properties by scavenging free radicals involved in peroxidation, preventing the expression of proteins associated with oxidative stress $(11,12)$. Recently, a mimic human-like type 1 DM model in BALB/C mice was established using multiple low doses (MLD) of streptozotocin (STZ), as previously described (17). This mouse strain is advantageous for the little to no influence from its genetic background, since most new cases of type $1 \mathrm{DM}$ are spasmodic and can develop in families with no previous history of DM (18). Furthermore, STZ has a short half-life, remaining biologically active in the serum for only 15 min following intravenous injection (19) and its acute toxicity to the liver can be neglected after hyperglycemia is induced (20). Consequently, after STZ is eliminated out of the body, any further functional impairments in the liver observed may be attributed to the effects of diabetic hyperglycemia $(19,20)$. Therefore, the MLD-STZ-induced model of $\mathrm{DM}$ is a suitable model for studying both the pathology of DM and complications related to the disease, as well as developing possible interventions for DM.

Using the aforementioned MLD-STZ-induced model of $\mathrm{DM}$, it was previously found that $P$. indica leaf ethanol extract (PILE) was able to reduce blood glucose levels, where the associated underlying mechanism in the diabetic pancreas, including suppression of cytokines and apoptotic markers, were elucidated (17). Notably, enzymes associated with total cholesterol, triglycerides, aspartate aminotransferase (AST), alanine aminotransferase (ALT), and alkaline phosphatase (ALP) were found to be significantly decreased in the serum of PILE-treated animals, indicating an improvement in liver function under diabetic conditions (17). Therefore, the present study aimed to test the hypothesis that PILE has the potential to ameliorate hepatocellular damage in STZ-induced diabetic mice further, that its potentially beneficial effects are associated with the attenuation of important molecular targets associated with oxidative stress, inflammation and apoptosis.

\section{Materials and methods}

Plant material. P. indica leaves were verified and maintained at the Herbarium, Department of Biology, Faculty of Science, Prince of Songkla University (PSU Herbarium; Hat Yai, Thailand). The voucher specimen number J.Nopparat-A. Nualla-ong 1 (PSU) was designated to the plants. For the preparation of the ethanol extract, dried leaves $(10 \mathrm{~g})$ of $P$. indica were extracted using $95 \%$ ethanol at $37^{\circ} \mathrm{C}$ for 3 days. The plant extract was concentrated and dried under reduced pressure using a rotary vacuum evaporator at $112 \mathrm{~mm} \mathrm{Hg}$ and $40^{\circ} \mathrm{C}$ and filtered using $0.45-\mu \mathrm{m}$ filters. PILEs were then stored at $4^{\circ} \mathrm{C}$ until further use. Various desired concentrations of PILE were prepared by dissolving with $5 \%(\mathrm{v} / \mathrm{v})$ Tween- 80 before use in the present study. The phytochemical component analysis of PILE by liquid chromatography-mass spectrometry and gas chromatography-mass spectrometry was recently published in a previous study (17).

Induction of diabetes in experimental animals. The experimental design and induction of diabetes was previously reported (17). Therefore, the present study represents further evaluation of our previous animal study. A total of 80 male BALB/C mice (5-6 weeks old) were purchased from Nomura Siam International Co., Ltd. The mice were maintained in the animal facility of PSU in a well-ventilated humidified room $\left(23^{\circ} \mathrm{C} \pm 2^{\circ} \mathrm{C}\right.$; humidity, $50 \% \pm 10 \%$; with alternating 12 -h light/dark cycles). The animals received water ad libitum and were fed standard chow. The experimental protocols described in this study were approved and guided by the Institutional Animal Care and Use Committee of Prince of Songkla University (MOE 0521.11/124). The mice were randomly assigned into one of the following four groups $(n=10$ per group): i) Group I (control), where the mice were intraperitoneally injected with $0.1 \mathrm{M}$ citrate buffer, $\mathrm{pH} 4.5$ (diluent for STZ; Sigma-Aldrich; Merck KGaA) and fed once daily with the diluent 5\% (v/v) Tween-80; ii) Group II (STZ), where the mice were intraperitoneally injected with STZ $(50 \mathrm{mg} / \mathrm{kg})$ for 5 consecutive days and fed once daily with diluent; iii) Group III [PILE $(50 \mathrm{mg} / \mathrm{kg})+\mathrm{STZ}$, where the mice were pretreated with a dietary supplement of $50 \mathrm{mg} / \mathrm{kg}$ PILE (PILE 50) for 2 weeks before receiving STZ injection $(50 \mathrm{mg} / \mathrm{kg})$; and iv) Group IV [PILE $(100 \mathrm{mg} / \mathrm{kg})+$ STZ], where the mice were pretreated with a dietary supplement of $100 \mathrm{mg} / \mathrm{kg}$ PILE (PILE 100) for 2 weeks before receiving STZ injection $(50 \mathrm{mg} / \mathrm{kg})$.

Following 2 weeks of pretreatment with the aforementioned diet, diabetes was induced with $50 \mathrm{mg} / \mathrm{kg} \mathrm{STZ} \mathrm{dissolved} \mathrm{in}$ $0.1 \mathrm{M}$ citrate buffer ( $\mathrm{pH} 4.5$ ) for 5 consecutive days (21). The first injection day was defined as day 0 . To confirm diabetic status, fasting blood glucose levels were measured in a drop of blood collected from the tail vein using a blood glucose meter (Accu-Chek Active test strips; Roche Diagnostics $\mathrm{GmbH}$ ) 3 days following the final STZ injection. All STZ-injected animals developed hyperglycemia (blood glucose levels $>200 \mathrm{mg} / \mathrm{dl}$ ) and were retained for further experimentation $(17,22)$. Animals in group III and IV continued to be fed with PILE 50 or PILE 100 by oral gavage once daily for 4 or 8 weeks. At the final 4- and 8-week time points, the mice were anesthetized with thiopental $(70 \mathrm{mg} / \mathrm{kg})$, following which euthanasia was immediately performed by cervical dislocation. The assessment criteria for confirmation of animal death included lack of heartbeat for $>5$ minutes, lack of movement and visible lack of breathing. Subsequently, the right and left lateral lobes of the liver were collected for further study.

Histological examination. Following sacrifice, the livers were immediately removed and fixed in $10 \%$ neutral formalin for $24 \mathrm{~h}$ at room temperature (RT). After fixation, the liver tissues were dehydrated in ascending grades of ethanol, cleared in xylene and embedded in paraffin blocks. Embedded liver tissues were cut into $5-\mu \mathrm{m}$-thick sections and stained with hematoxylin and eosin for $1.5 \mathrm{~h}$ at RT according to standard laboratory procedures. Histological observations were performed under light microscopy (magnifications, x200 and 
x400; Olympus D73 equipped with CellSens software v1.16; Olympus Corporation).

Biochemical analysis of oxidative stress markers. The expression levels of the antioxidant enzymes SOD (cat. no. 19160; Sigma-Aldrich; Merck KGaA), CAT (cat. no. 707002; Cayman Chemical Company) and MDA (a marker of lipid peroxidation; cat. no. MAK085; Sigma-Aldrich; Merck KGaA) were measured using corresponding assay kits. Briefly, liver tissues were isolated from the euthanized mice, rinsed with PBS ( $\mathrm{pH}$ 7.4), homogenized in lysis buffer (150 mM Tris; $\mathrm{pH} 7.2)$ and centrifuged at $10,000 \mathrm{x}$ for $15 \mathrm{~min}$ at $4^{\circ} \mathrm{C}$. The supernatants were further processed according to the manufacturer's protocols.

Immunohistochemical analysis. Immunohistochemistry (IHC) was conducted according to the manufacturer's instructions (Vectastain Elite ABC-HRP kit; cat. no. PK-6200; Vector Laboratories, Inc.; Maravai Life Sciences). The following antibodies were purchased: rabbit polyclonal anti-SOD (1:200; cat. no. ab13498; Abcam), rabbit monoclonal anti-IL-6 (1:400; cat. no. 12912; Cell Signaling Technology, Inc.), rabbit polyclonal anti-TNF- $\alpha$ (1:200; cat. no. ab6671; Abcam) and mouse monoclonal anti-TGF- $\beta 1$ (1:200; cat. no. MAB240, R\&D Systems, Inc.). Briefly, liver tissue sections were deparaffinized with xylene and rehydrated in a graded ethanol series. Antigen retrieval was performed by heating the tissues at $95^{\circ} \mathrm{C}$ with citrate buffer ( $\mathrm{pH}$ 6.0) for $20 \mathrm{~min}$, followed by blocking endogenous peroxidase activity in $0.3 \% \mathrm{H}_{2} \mathrm{O}_{2}$ (in methanol) for $30 \mathrm{~min}$ at RT. Following three $5 \mathrm{~min}$ washes with PBS with $0.1 \%$ Triton X-100 (PBST), normal horse serum (Vector Laboratories, Inc.; Maravai Life Sciences) was applied for $1 \mathrm{~h}$ at RT. Incubation with primary antibodies against SOD, CAT, IL-6, TNF- $\alpha$ and TGF- $\beta 1$ was performed overnight at $4^{\circ} \mathrm{C}$ in a humidified chamber. The tissues were then rinsed with PBST and incubated with a biotinylated horse anti-mouse/rabbit immunoglobulin G universal secondary antibody (Vectastain Elite ABC-HRP kit; cat. no. PK-6200, Vector Laboratories, Inc.; Maravai Life Sciences) for $1 \mathrm{~h}$ at RT. After washing with PBST, the tissues were stained with diaminobenzidine (DAB), rinsed with distilled water and counterstained with hematoxylin for $1 \mathrm{~min}$ at RT. The sections were then dehydrated in a series of graded ethanol, cleared in xylene and mounted for light microscopic examination. To confirm specific labelling, negative control staining was performed by incubating the tissue with PBS instead of primary antibody.

Morphometric analysis. Immunopositive staining was represented by brown staining and images were photographed at x400 magnification. The percentage of the immunopositive area (\% IA) was calculated in the captured representative fields (a standard area, 460,096 $\mu \mathrm{m}^{2}$ ) using ImageJ software version $1.52 \mathrm{u}$ (National Institutes of Health). Digital images (a total of 36 fields per experimental group: 3 fields per section, 3 sections per mouse with a $20-\mu \mathrm{m}$ interval between each section, 4 mice per group) were randomly selected, followed by deconvolution using the color deconvolution plug-in, resulting in separate DAB (brown), hematoxylin (blue) and a complimentary image. On the composite hematoxylin-DAB images, the photographs were set to 8-bit where the threshold was then adjusted for DAB detection according to intensity. The threshold parameters remained consistent for all images. The \% IA for each group was calculated by dividing the sum of the IA by the sum of the area of each microscopic field multiplied by 100 (23).

Western blot analysis. The antibodies used for western blotting were obtained from the following sources: Rabbit polyclonal anti-CAT (1:1,000; cat. no. ab16731; Abcam); rabbit monoclonal anti-NF-кB p65 (1:1,000; cat. no. 8242; Cell Signaling Technology, Inc.); rabbit polyclonal anti-caspase-3 (1:1,000; cat. no. 9662; Cell Signaling Technology, Inc.); mouse monoclonal anti-caspase-9 (1:1,000; cat. no. 9508; Cell Signaling Technology, Inc.); rabbit monoclonal anti-Bcl-2 (1:1,000; cat. no. 3498; Cell Signaling Technology, Inc.); rabbit monoclonal anti-PKC (1:1,000; cat. no. ab179521; Abcam) and rabbit polyclonal anti- $\beta$-actin (1:3,000; cat. no. ab8227; Abcam). The liver tissues were lysed and homogenized in ice-cold RIPA buffer (Sigma-Aldrich; Merck-KGaA) supplemented with protease inhibitor cocktail (Merck KGaA). Following centrifugation at $14,000 \times \mathrm{g}$ for $30 \mathrm{~min}$ at $4^{\circ} \mathrm{C}$, the supernatant was collected and total protein was quantified using a bicinchoninic acid protein assay kit (Pierce; Thermo Fisher Scientific, Inc.). The samples ( $\sim 50 \mu \mathrm{g}$ each) were separated on $12 \% \mathrm{SDS} / \mathrm{PAGE}$ and transferred to PVDF membranes (Merck KGaA). The membranes were blocked with $5 \%$ skim milk for $1 \mathrm{~h}$ at RT and then probed with primary antibodies against SOD, CAT, TGF- $\beta 1$, NF- $\kappa$ Bp65, PKC, caspase-3, caspase-9, Bcl-2 and $\beta$-actin overnight at $4^{\circ} \mathrm{C}$. Subsequently, the membranes were incubated at RT for $1 \mathrm{~h}$ with appropriate horseradish peroxidase (HRP)-linked secondary antibodies (1:5,000; goat anti-rabbit IgG; cat. no. A3687, rabbit anti-mouse IgG; cat. no. A9917, Sigma-Aldrich; Merck KGaA). Protein signal was visualized using Luminata Crescendo Western HRP substrate (Merck KGaA) according to the manufacturer's instructions. The density of each of the immunoreactive bands was analyzed using the ImageJ software version $1.52 \mathrm{u}$ (National Institutes of Health). The data were normalized to the density of each $\beta$-actin band, calculated as a fold change compared with the normal control group, and then analyzed.

Statistical analysis. All results are expressed as the mean \pm SEM unless otherwise stated. Statistical analysis was performed using GraphPad Prism 7.0 (GraphPad Software, Inc.). The data from multiple groups were compared using one-way ANOVA followed by Tukey's multiple comparisons test. $\mathrm{P}<0.05$ was considered to indicate a statistically significant difference.

\section{Results}

PILE treatment alleviates liver hypertrophy and hepatohistological changes in STZ-induced diabetic mice. The liver is highly susceptible to damage from STZ-induced diabetes (7). To explore the STZ-associated diabetic phenotype in the present study, the incidence of liver hypertrophy was investigated (Fig. 1A and B). A significant $(\mathrm{P}<0.0001)$ decrease in the absolute liver weight was identified in the STZ mice compared with the controls at both time points (Fig. 1A). However, a significant $(\mathrm{P}<0.01)$ increase in the absolute liver weight was 

A
Control
PILE $50+$ STZ
STZ
PILE $100+$ STZ
B
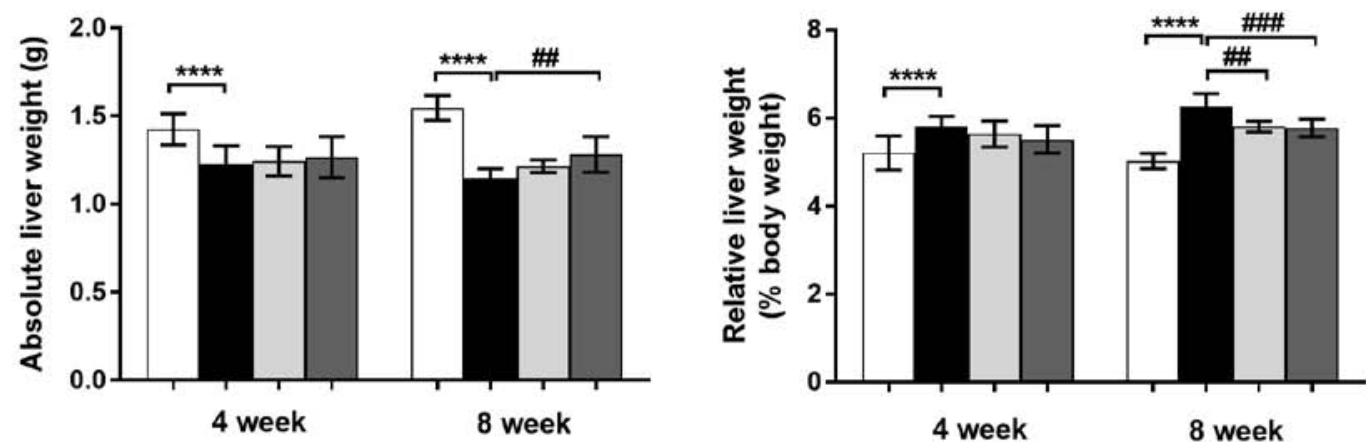

C

Control STZ

4 week

8 week

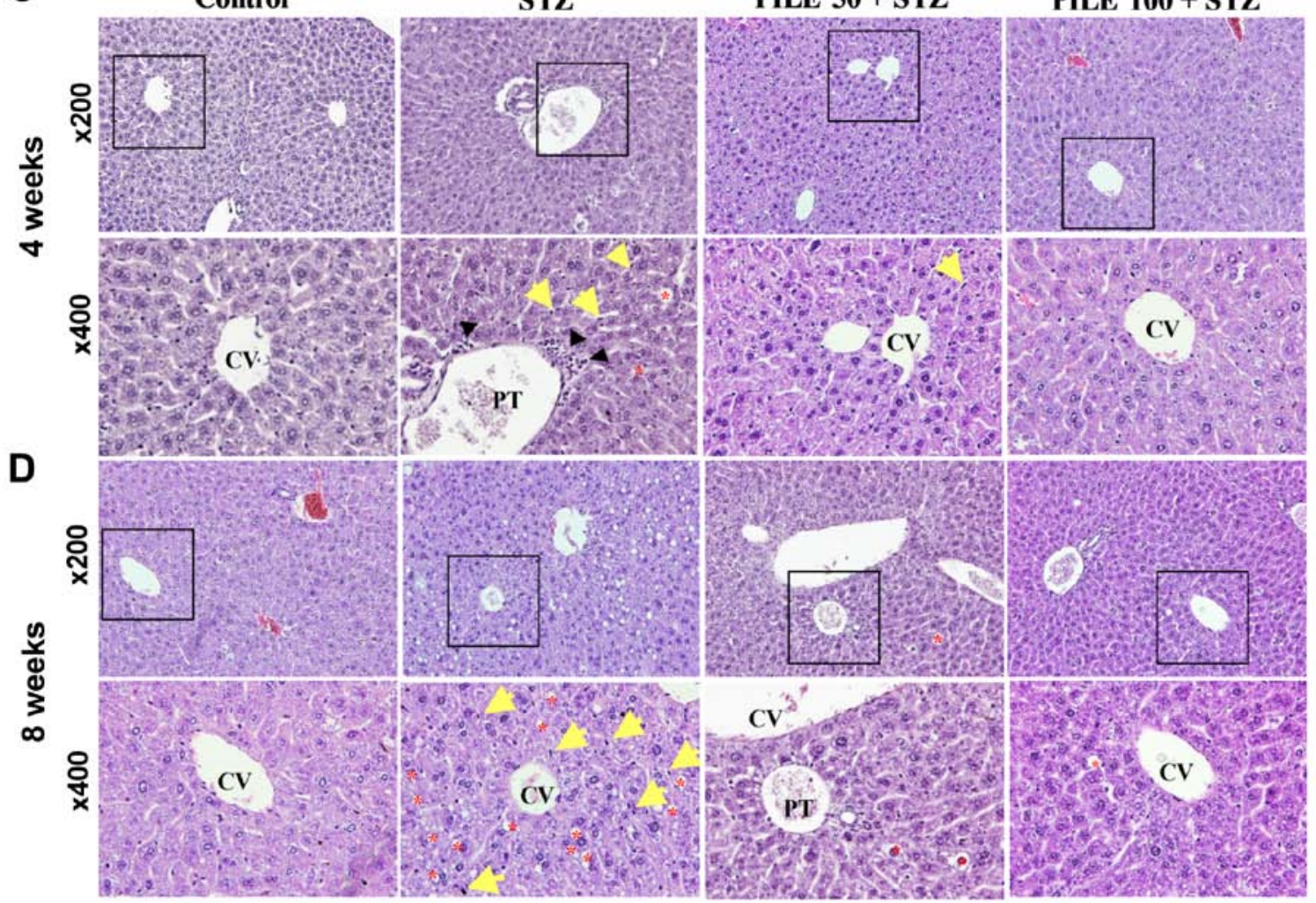

Figure 1. Effects of PILE treatment on the liver phenotype under diabetic conditions. (A) Absolute liver weight. (B) Relative liver-to-body weight ratio. Representative images of hepatic hematoxylin and eosin staining at the (C) 4- and (D) 8-week time points The regions within the squares are shown at progressively higher magnification (x400) to illustrate the pattern of liver damage. Yellow arrows indicate the locations of Kupffer cells; black arrowheads indicate monocytes and red asterisks mark the accumulation of lipid droplets. Magnifications, $\mathrm{x} 200$ and $\mathrm{x} 400$. Values represent the mean $\pm \mathrm{SD}$. $\mathrm{n}=10$. ${ }^{* * * *} \mathrm{P}<0.0001$; ${ }^{\# \#} \mathrm{P}<0.01$ and ${ }^{\# \#} \mathrm{P}<0.001$. PILE, Pluchea indica leaf ethanol extract; PT, portal triad; CV, central vein; STZ, streptozotocin; PILE 50, mice treated with $50 \mathrm{mg} / \mathrm{kg}$ PILE; PILE 100; mice treated with $100 \mathrm{mg} / \mathrm{kg}$ PILE.

noted in the mice treated with PILE 100 for 8 weeks compared with the STZ animals (Fig. 1A). The liver hypertrophy was revealed when the ratio of liver weight with respect to body weight was calculated (Fig. 1B). The ratio was significantly higher $(\mathrm{P}<0.0001)$ in STZ groups compared with control groups at both time points. This phenomenon was ameliorated following PILE $50(\mathrm{P}<0.01)$ and PILE $100(\mathrm{P}<0.001)$ treatments for 8 weeks (Fig. 1B). These results suggested that the treatment with PILE has reversed the progressive changes of liver weight in diabetic mice.

The presence of liver hypertrophy was reflected in the histological alterations observed in the STZ mice compared with control animals (Fig. 1C and D). Liver sections from the control mice exhibited normal liver sinusoids (not dilated) where the hepatocyte architecture was arranged into sheets radiating from the central vein (Fig. 1C and D). 
By contrast, the livers of the STZ group exhibited marked hepatocyte degeneration (Fig. 1C and D), particularly at the central areas; the disappearance of cell borders, disorganized hepatic cords, dilated sinusoids and the presence of Kupffer cells and monocytes were also observed (Fig. 1C). Following progression to the 8-week time point, the hepatocytes of the STZ mice developed a vacuolated cytoplasm with a ground-glass appearance and markedly increased accumulation of lipid droplets (Fig. 1D). The livers of the PILE 50 and PILE 100 groups exhibited less vacuolar degeneration, preservation of hepatocyte structure, where the presence of Kupffer cells was less apparent compared with the livers of STZ-only mice (Fig. 1C and D). These observations provided evidence of diabetes-associated histopathological alterations, where PILE treatment exerted positive counteractive effects on STZ-induced liver injury.

PILE treatment reduces the expression of markers associated with oxidative stress in the liver. Oxidative stress is a common consequence of prolonged hyperglycemia, as previously observed in STZ-induced diabetic animals (7). Therefore, the present study investigated the effects of PILE treatment on STZ-induced oxidative damage by measuring levels of antioxidant enzymes SOD, CAT, in addition to MDA, a surrogate marker for oxidative stress, in liver homogenates. Biochemical analyses revealed a significant reduction in the levels of $\mathrm{SOD}(\mathrm{P}<0.0001$; Fig. 2A) and CAT $(\mathrm{P}<0.01$ and $\mathrm{P}<0.0001,4$ and 8 weeks, respectively; Fig. $2 \mathrm{~B})$, whilst those of MDA were significantly increased $(\mathrm{P}<0.05$ and $\mathrm{P}<0.001,4$ and 8 weeks, respectively; Fig. 2C) in STZ animals compared with those in control animals. However, there were significant reversals on the STZ-induced effects on the levels of SOD, CAT (both $\mathrm{P}<0.01,8$ weeks) and MDA $(\mathrm{P}<0.05$ and $\mathrm{P}<0.001,4$ and 8 weeks, respectively) following treatment with PILE 100 (Fig. 2A-C). Western blot analysis revealed a significant increase in the levels of $\mathrm{SOD}(\mathrm{P}<0.0001)$ and CAT $(\mathrm{P}<0.0001)$ in the livers of the STZ mice, compared with control mice, at both time points (Fig. 2D-F). Treatment with PILE 100 resulted in a significant reduction in SOD $(\mathrm{P}<0.05$ and $\mathrm{P}<0.01,4$ and 8 weeks, respectively; Fig. 2E) and CAT $(\mathrm{P}<0.05$, both time points; Fig. $2 \mathrm{~F})$ compared with STZ mice. PILE 50 exerted a less pronounced effect on CAT compared with PILE 100, especially at the 4-week time point (Fig. 2E and F).

Hepatic expression of SOD was subsequently validated using IHC. The liver tissues of untreated STZ mice exhibited significantly stronger SOD staining compared with that in control mice $(\mathrm{P}<0.0001)$, which were predominantly distributed in the hepatocytes around the central and portal triad areas (Fig. 2G). Conversely, at the 8-week time point, the PILE 50 $(\mathrm{P}<0.05)$ and PILE $100(\mathrm{P}<0.05)$ groups showed significantly reduced percentages of SOD staining compared with those in the untreated STZ mice (Fig. 2H). These findings suggested that PILE exerted protective effects against oxidative stress in STZ-induced diabetic mice.

PILE treatment modulates the upregulation of markers associated with inflammation in the liver. Imbalance between the oxidative stress and antioxidant defense system is closely associated with the inflammatory response (24). This is evident from the release of multiple inflammatory factors, resulting in local inflammation and tissue injury $(4,5,24)$. The expression of proinflammatory cytokines IL- 6 and TNF- $\alpha$ in the diabetic liver was therefore investigated by western blotting (Fig. 3A-C) and immunohistochemical staining (Fig. 3D-G). STZ induced a significant increase in hepatic IL-6 levels at both time points compared with those in control mice $(\mathrm{P}<0.0001$; Fig. 3A and B). By contrast, levels of IL-6 were found to be significantly reduced by PILE $50(\mathrm{P}<0.05)$ at 4-week time point and PILE 100 at the $4-(\mathrm{P}<0.01)$ and 8 -week $(\mathrm{P}<0.001)$ time points compared with those in the untreated STZ mice (Fig. 3A and B). The immunoreactivity of hepatic IL- 6 was also revealed to be significantly increased $(\mathrm{P}<0.0001)$ in STZ animals compared with control mice at both time points, which was significantly reversed by both PILE $50(\mathrm{P}<0.05)$ and PILE $100(\mathrm{P}<0.01)$ at the 8-week time point compared with that in the STZ mice (Fig. 3D and F).

Similarly, levels of hepatic TNF- $\alpha$ were also found to be significantly increased $(\mathrm{P}<0.01$ and $\mathrm{P}<0.0001,4$ and 8 weeks, respectively) in the diabetic liver compared with those in the control mice (Fig. 3A and C), which were significantly reduced by PILE $50(\mathrm{P}<0.05,8$ weeks $)$ and PILE $100(\mathrm{P}<0.05$ and $\mathrm{P}<0.0001,4$ and 8 weeks, respectively). TNF- $\alpha$ immunoreactivity manifested as a large area of accumulation at the center of the cells and around the portal vein, particularly at the innermost cell layer surrounding the vein (STZ group; Fig. 3E), which was not observed in the control group (Fig. 3E). Although the reduction in TNF- $\alpha$ staining intensity was not significant in the PILE 50 or 100 groups at the 4-week time point, a significant reduction was noted following treatment with PILE 100 at the 8-week time point compared with that in the STZ group $(\mathrm{P}<0.05$; Fig. $3 \mathrm{E}$ and $\mathrm{G})$. These results indicated that PILE treatment alleviated the hepatic inflammatory response.

PILE treatment attenuates the STZ-induced upregulation of TGF- $\beta 1, N F-\kappa B$ p 65 and PKC expression in the liver. The phosphorylated p65 subunit of NF- $\kappa \mathrm{B}(\mathrm{NF}-\kappa \mathrm{B}$ p65) is a sensor of the immune response and serves a pivotal role in oxidative stress (25). Therefore, the potential association between STZ-induced oxidative damage and the upregulation of hepatic $\mathrm{NF}-\kappa \mathrm{B}$ p 65 was investigated. Western blotting confirmed that hepatic NF- $\mathrm{NB}$ p 65 protein expression was significantly increased in untreated STZ mice compared with that in control mice $(\mathrm{P}<0.01$ and $\mathrm{P}<0.0001$, 4 and 8 weeks, respectively; Fig. 4A and B). By contrast, treatment with PILE 100 significantly counteracted this phenomenon at both time points $(\mathrm{P}<0.05$ and $\mathrm{P}<0.01,4$ and 8 weeks, respectively; Fig. 4A and B). Although PILE 50 also resulted in $\mathrm{NF}-\kappa \mathrm{B}$ p 65 downregulation at 4 and 8 weeks, the effect was not found to be statistically significant compared with the STZ group (Fig. 4A and B). In addition, NF- $\kappa \mathrm{B}$ p65 activation involves alterations to its downstream targets, TGF- $\beta 1$ and PKC $(9,26)$. In the present study, TGF- $\beta 1$ and PKC protein expression were significantly upregulated in the STZ group compared with those in the control mice at both time points $(\mathrm{P}<0.0001$; Fig. $4 \mathrm{~A}, \mathrm{C}$ and $\mathrm{D})$, coinciding with the increase in NF- $\mathrm{B}$ p65 aforementioned. However, the upregulation of TGF- $\beta 1(\mathrm{P}<0.01$ and $\mathrm{P}<0.05,4$ and 

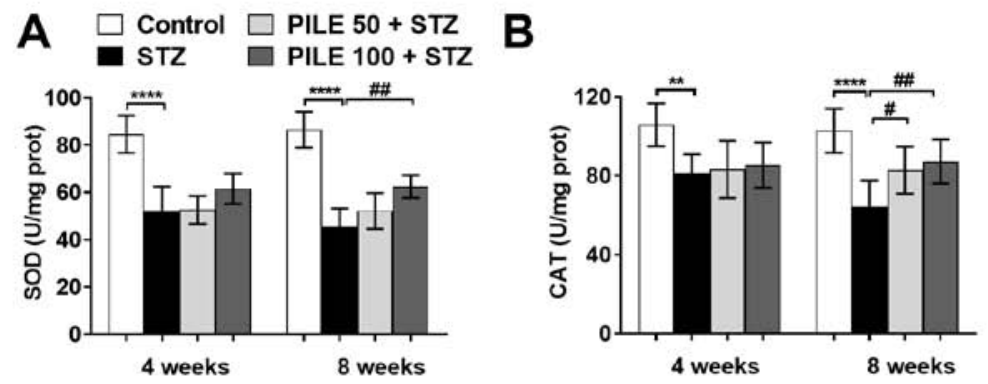

C
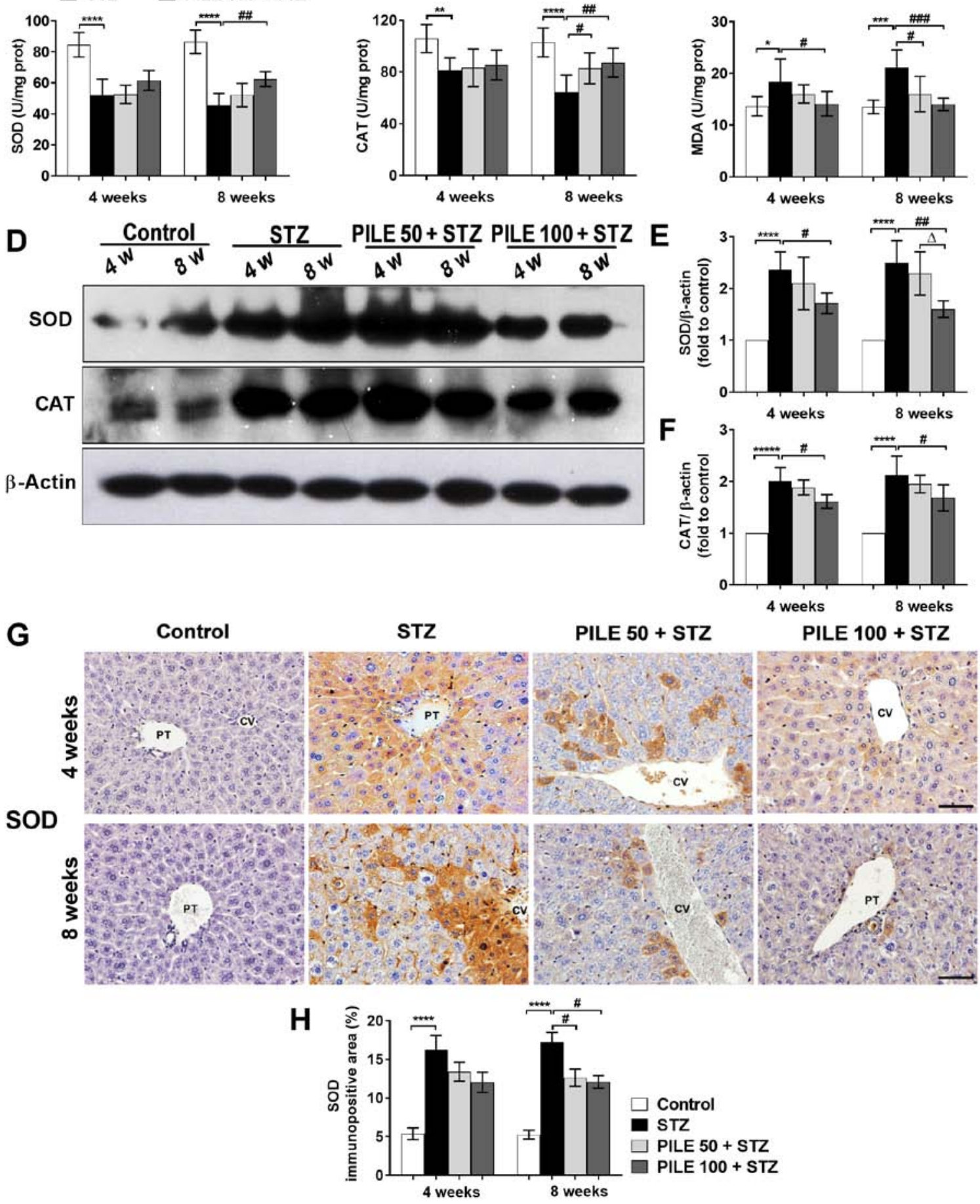

Figure 2. Effects of PILE treatment on the hepatic oxidative status. Liver tissues from the different treatment groups were isolated at 4 and 8 weeks, following which the antioxidant properties of PILE were assessed. Biochemical analysis of (A) SOD, (B) CAT and (C) MDA levels in liver homogenates. $\mathrm{n}=6$. (D) Representative western blot images of hepatic SOD and CAT expression. Densitometric quantification of (E) SOD and (F) CAT expression normalized to that of $\beta$-actin. $n=4$. (G) Representative immunohistochemical images of hepatic SOD staining at the 4-and 8-week time points. (H) Quantification of the percentage of immunopositive areas of SOD staining. $n=4$. Magnification, $x 400$. Data are presented as the mean \pm SD for biochemical analysis and mean \pm SEM for immunohistochemistry and western blot assays. ${ }^{*} \mathrm{P}<0.05 ;{ }^{* *} \mathrm{P}<0.01 ;{ }^{* * * *} \mathrm{P}<0.001$ and ${ }^{* * * *} \mathrm{P}<0.0001 ;{ }^{*} \mathrm{P}<0.05 ;{ }^{* \#} \mathrm{P}<0.01$ and ${ }^{\# \# \#} \mathrm{P}<0.001 ;{ }^{\Delta} \mathrm{P}<0.05$. PILE Pluchea indica leaf ethanol extract; SOD, superoxide dismutase; CAT, catalase; MDA, malondialdehyde; PT, portal triad; CV, central vein; STZ, streptozotocin; PILE 50, mice treated with 50 mg/kg PILE; PILE 100; mice treated with $100 \mathrm{mg} / \mathrm{kg}$ PILE; w, weeks; prot, protein.

8 weeks, respectively) and $\mathrm{PKC}(\mathrm{P}<0.05$ and $\mathrm{P}<0.0001$, 4 and 8 weeks, respectively) was reversed by PILE 100 (Fig. 4C and D). Furthermore, at the 8-week time point, a significant reduction in PKC expression was observed in the PILE 100 group compared with that in the PILE 50 group $(\mathrm{P}<0.0001$; Fig. 4A and D). 
A
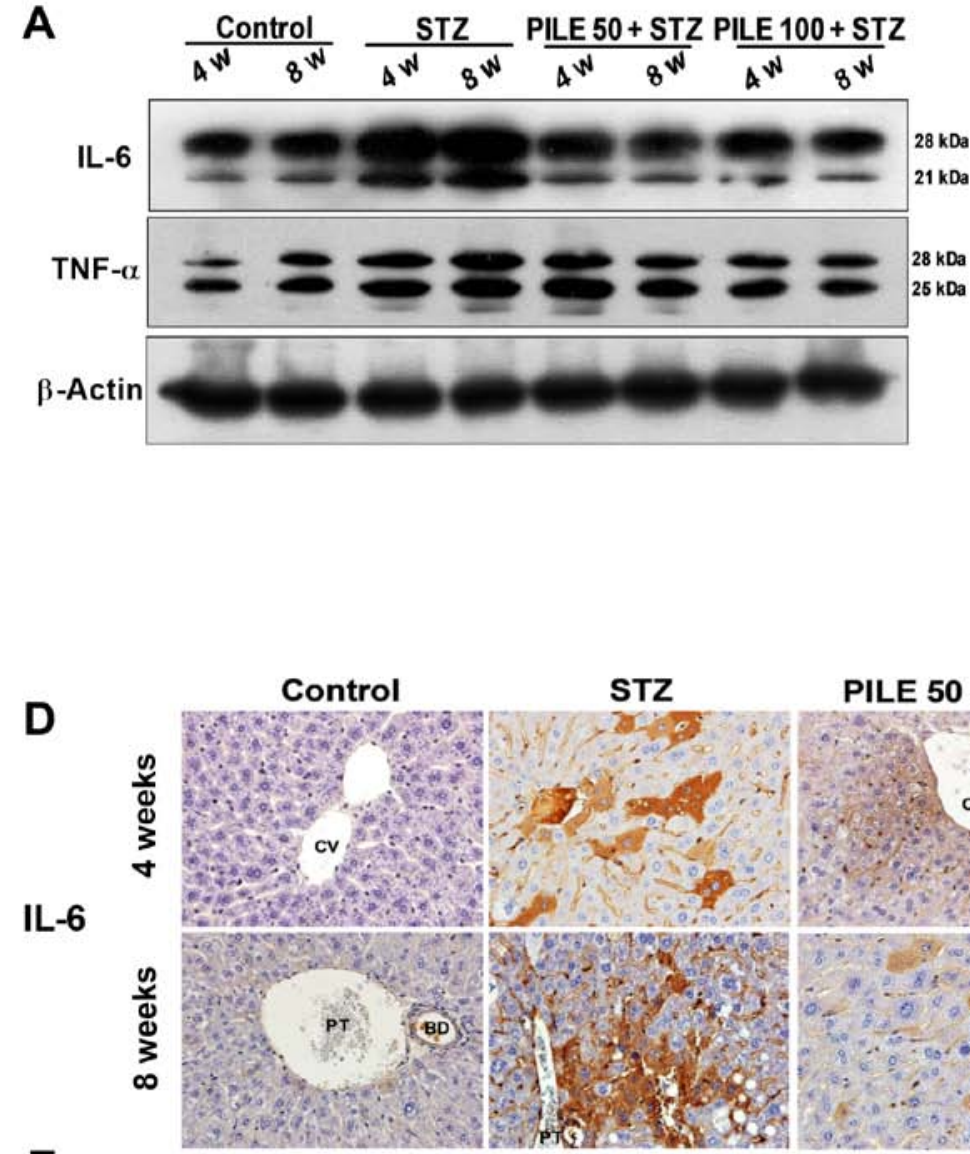

E

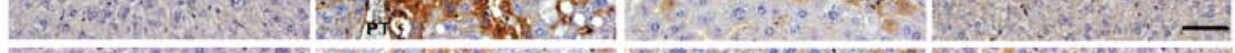

B $\square$ Control $\square$ PILE $50+$ STZ

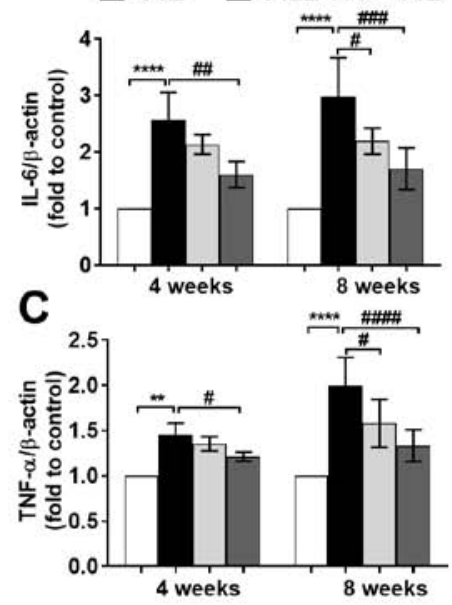

PILE $50+$ STZ PILE $100+$ STZ

TNF- $\alpha$

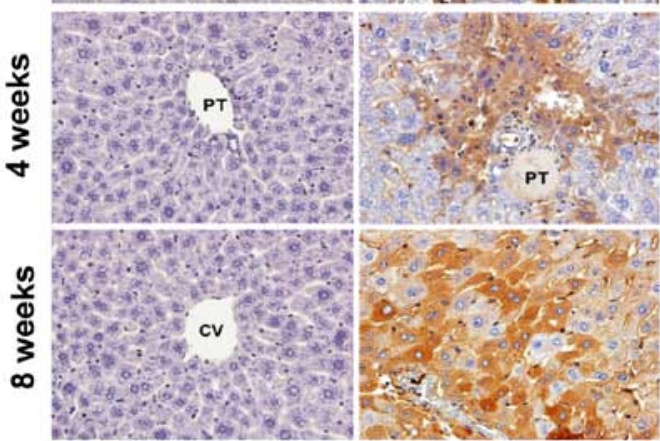

$\mathbf{F}$
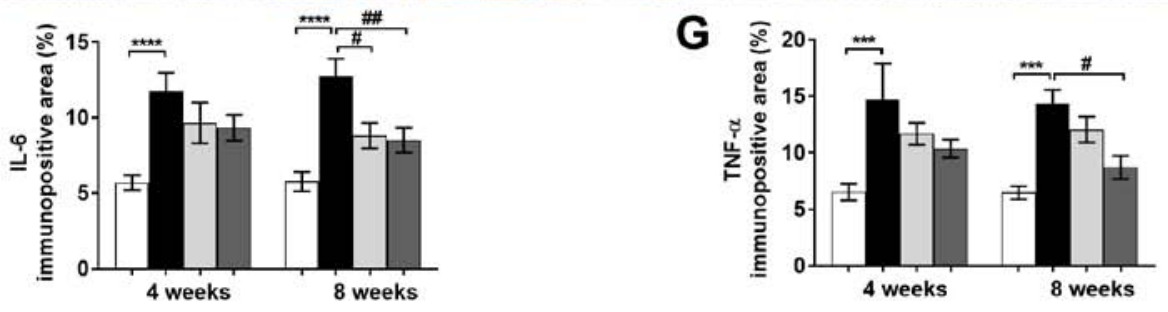

Figure 3. Effects of PILE treatment on hepatic IL-6 and TNF- $\alpha$ levels in STZ mice. (A) Representative images of western blot analysis of hepatic IL-6 and TNF- $\alpha$ expression. Densitometric quantification of (B) IL-6 and (C) TNF- $\alpha$ expression normalized to $\beta$-actin. Representative images of (D) hepatic IL-6 and (E) TNF- $\alpha$ immunoreactivity at the 4- and 8-week time points. Quantification of the percentage immunopositive areas of (F) IL-6 and (G) TNF- $\alpha$ staining.

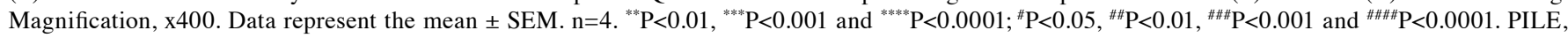
Pluchea indica leaf ethanol extract; IL-6, interleukin 6; TNF- $\alpha$, tumor necrosis factor- $\alpha$; STZ, streptozotocin; PT, portal triad; CV, central vein; BD, bile duct; PILE 50, mice treated with $50 \mathrm{mg} / \mathrm{kg}$ PILE; PILE 100; mice treated with $100 \mathrm{mg} / \mathrm{kg}$ PILE; w, weeks.

According to immunohistochemical staining, TGF- $\beta 1$ expression was predominantly localized to hepatocytes close to the central and portal veins (Fig. 4E). The intensity of TGF- $\beta 1$ staining significantly increased in the livers of untreated STZ mice compared with that in control mice $(\mathrm{P}<0.0001)$, which was significantly reversed by PILE 100 treatment $(\mathrm{P}<0.05$; Fig. 4F). In summary, these observations suggest that PILE treatment attenuated the inflammatory 


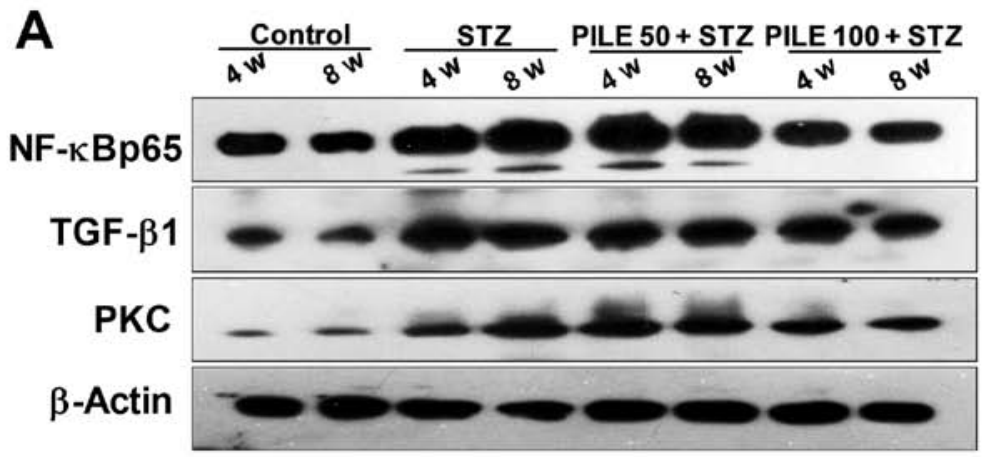

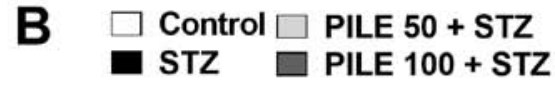

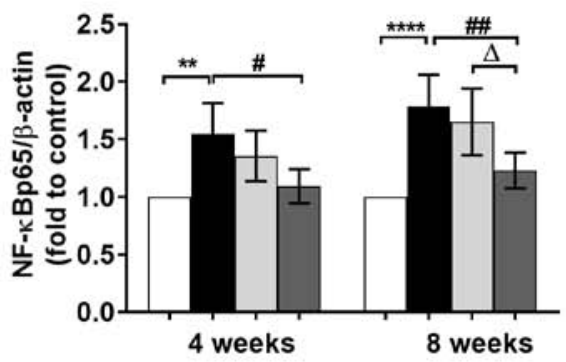

C

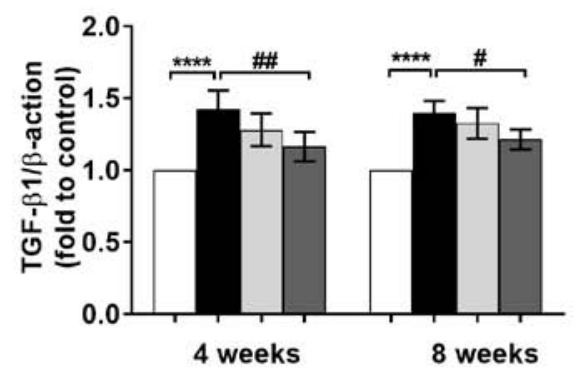

D

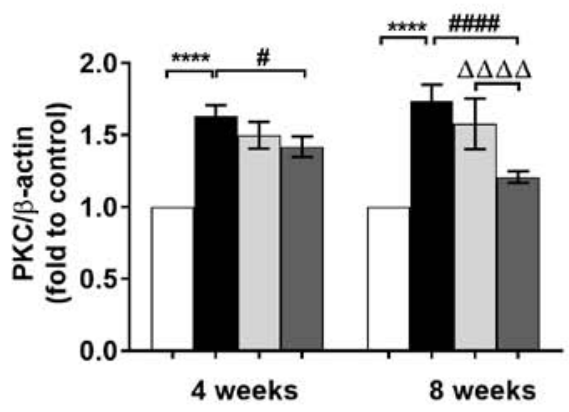

$\mathbf{E}$

Control

STZ

PILE $50+$ STZ

PILE 100 + STZ
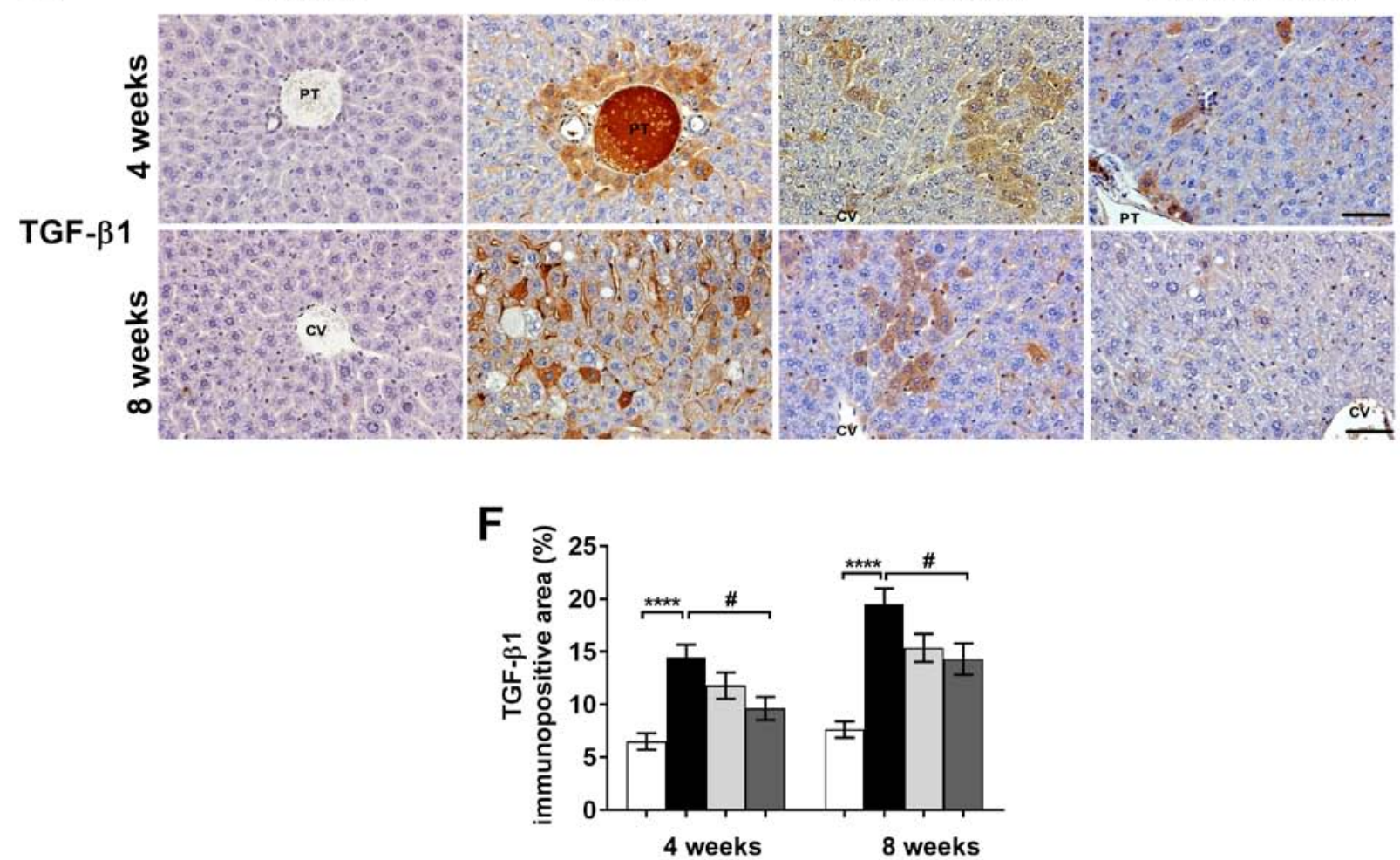

Figure 4. Effects of PILE treatment on hepatic TGF- $\beta 1$, NF- $\mathrm{\kappa B}$ p65 and PKC expression in STZ mice. (A) Representative western blot images of hepatic NF-KB p65, TGF- $\beta 1$ and PKC expression. Densitometric quantification of (B) NF-KB p65, (C) TGF- $\beta 1$ and (D) PKC expression levels normalized to $\beta$-actin. (E) Representative TGF- $\beta 1$ immunohistochemical staining images of the liver tissues from different groups at 4- and 8-week time points. (F) Quantification of the percentage immunopositive areas of TGF- $\beta 1$ staining among the four experimental groups. Magnification, $\mathrm{x} 400$. Data were presented as the mean \pm SEM. $\mathrm{n}=4 .{ }^{* *} \mathrm{P}<0.01$ and ${ }^{* * * * *} \mathrm{P}<0.0001 ;{ }^{\# P} \mathrm{P}<0.05,{ }^{\# \#} \mathrm{P}<0.01$ and ${ }^{\# \# \# *} \mathrm{P}<0.0001 ;{ }^{\Delta} \mathrm{P}<0.05$ and ${ }^{\Delta \Delta \Delta \Delta} \mathrm{P}<0.0001$. PILE, Pluchea indica leaf ethanol extract; TGF- $\beta 1$, transforming growth factor- $\beta 1$; PKC, protein kinase C; STZ, streptozotocin; PT, portal triad; CV, central vein; BD, bile duct; PILE 50, mice treated with 50 $\mathrm{mg} / \mathrm{kg}$ PILE; PILE 100; mice treated with $100 \mathrm{mg} / \mathrm{kg}$ PILE; w, weeks.

response in STZ-induced diabetic mice by downregulating $\mathrm{NF}-\kappa \mathrm{B}$ p65 and its downstream effectors TGF- $\beta 1$ and PKC.
PILE treatment reduces levels of caspase-associated apoptotic proteins in the liver. Apoptosis is a major pathway 

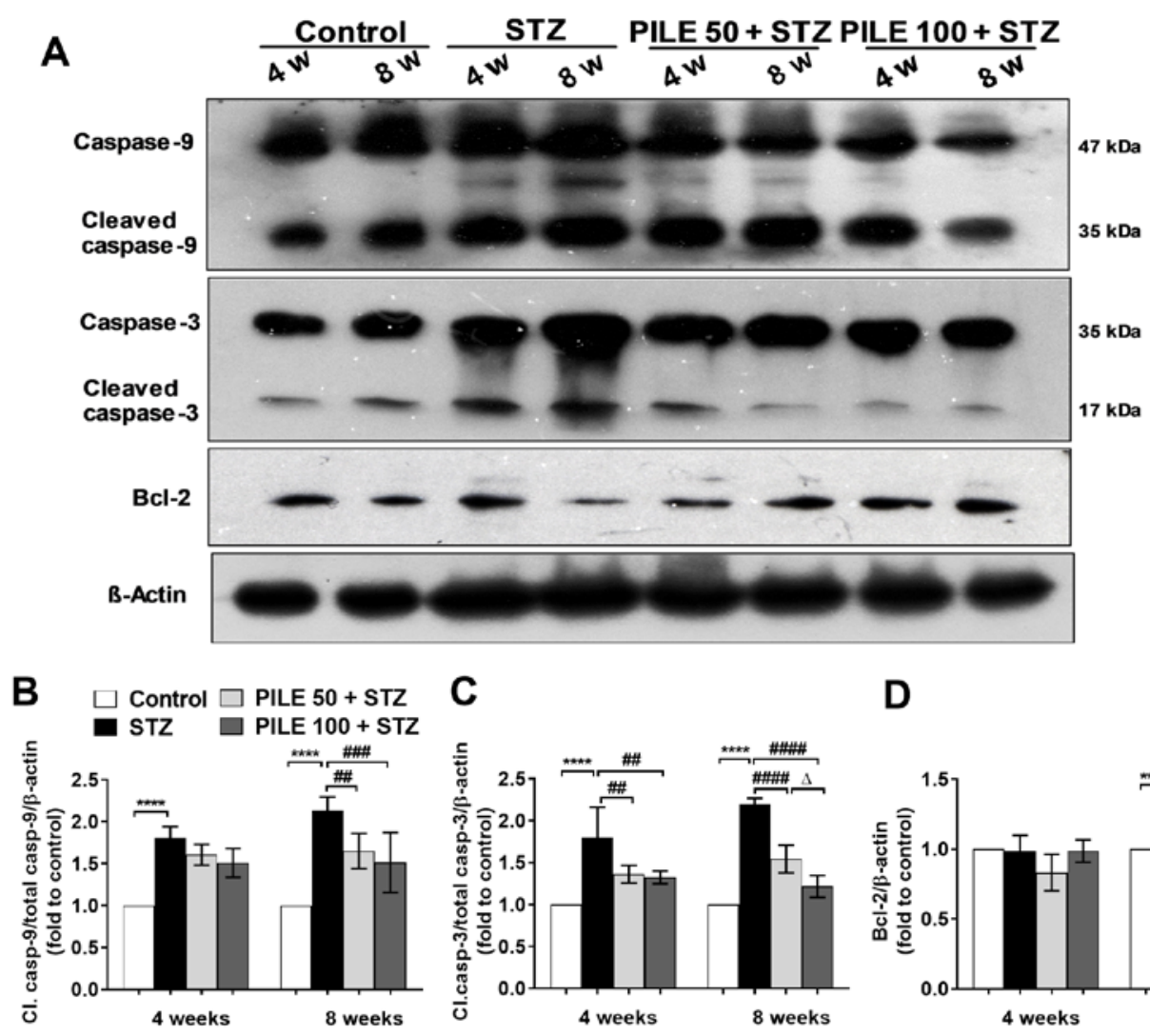

D

E

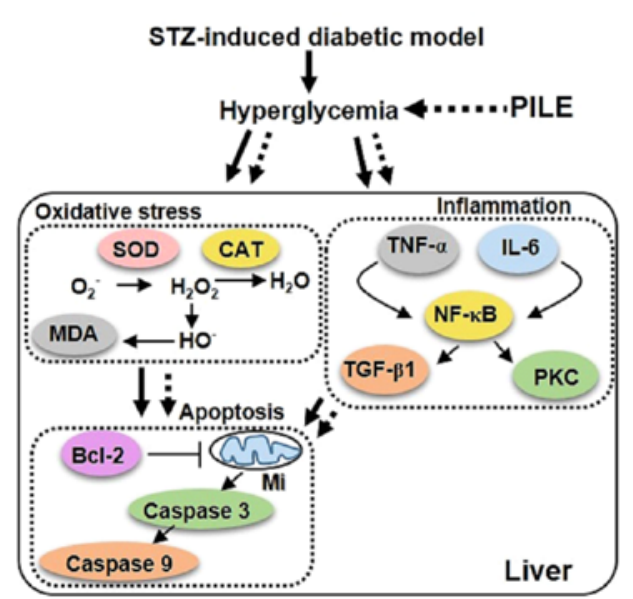

Figure 5. Effects of PILE on apoptosis in the STZ mouse liver. (A) Representative western blot images of hepatic protein expression of total and cleaved caspase-9, caspase-3 and Bcl-2. Densitometric quantification of (B) cleaved and total caspase-9, (C) cleaved and total caspase-3 and (D) Bcl-2 expression normalized to $\beta$-actin. (E) Summary schematic diagram and proposed roles of PILE against oxidative stress markers, inflammation regulators and apoptosis in the hepatic tissues of STZ-induced diabetic mice. Solid lines indicate increase in action or synthesis; dashed lines indicate decrease or inhibition of action or synthesis. Values represent the mean \pm SEM. $\mathrm{n}=4 .{ }^{* * * * *} \mathrm{P}<0.0001 ;{ }^{\# \#} \mathrm{P}<0.01,{ }^{\# \# \#} \mathrm{P}<0.001$ and ${ }^{\# \# \# \#} \mathrm{P}<0.0001 ;{ }^{\Delta} \mathrm{P}<0.05$ and ${ }^{\Delta \Delta \Delta} \mathrm{P}<0.001$. PILE. Pluchea indica leaf ethanol extract; STZ, streptozotocin; Mi, mitochondria; Cl, cleaved; PILE 50, mice treated with $50 \mathrm{mg} / \mathrm{kg}$ PILE; PILE $100 ;$ mice treated with $100 \mathrm{mg} / \mathrm{kg}$ PILE. SOD, superoxide dismutase; CAT, catalase; MDA, malondialdehyde; TNF- $\alpha$, tumor necrosis factor- $\alpha$; IL-6, interleukin- 6 ; TGF- $\beta 1$, transforming growth factor- $\beta 1$; PKC, protein kinase $\mathrm{C}$.

that is commonly involved in liver dysfunction (6). Therefore, western blot analysis was performed to elucidate the protective effects of PILE on hepatocyte apoptosis, in addition to the extent of inflammation-mediated hepatic injury (Fig. 5A-D). Compared with the control group, mice in the STZ group exhibited significantly increased levels of cleaved caspase- 9 and -3 at both time points $(\mathrm{P}<0.0001$; Fig. 5A-C). PILE 100 significantly suppressed both cleaved caspase-9 $(\mathrm{P}<0.001$,
8 weeks) and $-3(\mathrm{P}<0.01$ and $\mathrm{P}<0.0001,4$ and 8 weeks, respectively). Although, PILE $50(\mathrm{P}<0.01)$ and PILE $100(\mathrm{P}<0.001)$ exerted a moderate effect on caspase-9 at the 8-week time point (Fig. 5B), theirs effect on caspase-3 was significantly more pronounced (both $\mathrm{P}<0.0001$ at 8 weeks; Fig. 5C).

To investigate the protective effects of PILE further, the expression of hepatic Bcl-2, an anti-apoptotic molecule, was also investigated (Fig. 5A and D). No significant changes were 
observed in the levels of Bcl-2 at the 4-week time point regardless of treatment. However, a significant reduction in hepatic Bcl-2 expression was apparent in the STZ group at the 8-week time point compared with that in control mice $(\mathrm{P}<0.0001$; Fig. 5D). PILE $50(\mathrm{P}<0.01)$ and PILE $100(\mathrm{P}<0.0001)$ significantly reversed the effects of STZ on Bcl-2 expression to nearly that of control levels (Fig. 5D). Significantly higher levels of $\mathrm{Bcl}-2$ expression were also observed in the PILE 100 group compared with those in the PILE 50 mice $(\mathrm{P}<0.001$; Fig. 5D). These results implicate a role of PILE in protecting against hepatic apoptosis in vivo.

\section{Discussion}

The liver is particularly susceptible to the effects of hyperglycemia-induced oxidative stress (5). The mechanisms promoting hepatocyte injury in the context of these risk factors are mainly linked to the balance of oxidative stress and inflammation (5). Previous experimental evidence showed that PILE can alleviate type 1 DM-related pathologies via a number of mechanisms, including the promotion of antioxidant (11), anti-inflammatory $(13,14)$ and anti-hyperglycemic $(15-17)$ effects. Considering the phytochemical components of PILE, it was previously reported, consistent with other studies, that it is a rich source of phenolic acids and flavonoids, particularly quercetin and resveratrol, known for their antioxidant and anti-inflammatory properties $(11,17,27-29)$. Mukhopadhyay and Prajapati (29) previously documented that quercetin has higher antioxidant activity compared with other well-known antioxidant molecules such as ascorbly and trolox, due to the number and positions of the free hydroxyl groups in its structure. In addition, our earlier findings indicated that PILE possesses anti-hyperglycemic activity (17). PILE mainly exerts this activity by four mechanisms: i) Acting as free radical scavengers in peroxidation and preventing the expression of oxidative stress-related proteins $(12,18,30)$; ii) improving liver carbohydrate metabolism (31); iii) improving glucose uptake through mediators of the insulin signaling pathway (23); and iv) possessing $\alpha$-glucosidase inhibitory effects, which can delay the breakdown of starch into glucose, increasing glucose uptake from the circulation, lowering blood glucose levels (32). Since a previous study reported that treatment with PILE preserved liver function by restoring AST, ALT and ALP levels in the mouse sera (17), the role of PILE treatment on hyperglycemia-induced liver damage was investigated in the present study. Therefore, the present study aimed to determine the dose- and time-dependent effects of PILE treatment to investigate its protective effects against hepatic damage in STZ-induced diabetic mice.

Firstly, hepatic abnormalities were demonstrated by measuring the relative liver weights of STZ animals compared with those of the normal control group, where STZ livers showed signs of hypertrophy. Histological examination revealed that liver sections obtained from untreated STZ mice exhibited severe deleterious changes to the hepatic architecture, including degeneration of hepatocytes, disorganization of hepatic cords, dilated sinusoids, the appearance of Kupffer cells and monocyte infiltration. Cytoplasm vacuolization was also observed in the STZ mice at the 8-week point, in addition to lipid droplets in the cytoplasm of hepatocytes (classified as
NAFLD) $(4,10)$. Since the present mouse model is not considered as an obesity model, this phenomenon may be due to hypoinsulinemia increasing the influx of fatty acids into the liver, accompanied by the low lipoprotein excretion capacity of the liver (33). Hyperlipidemia may have also influenced fatty liver formation (34). However, fewer pathological changes and improved liver architecture were observed in PILE-pretreated diabetic mice, with reduced liver fatty deposits and Kupffer cell infiltration, indicating the protective effects of PILE treatment against the hepatic damage associated with diabetes.

Hyperglycemia is a primary cause of increased ROS generation, leading to oxidative stress $(4,7)$. In the present study, the occurrence of oxidative stress was assessed by the detection of key antioxidant enzymes in the liver tissue. Decreases in SOD and CAT expression, in addition to increases in those of MDA, were observed in the liver tissues of STZ-induced mice. Following treatment with PILE 100, the effects of STZ on the levels of these oxidative markers were found to be significantly reversed. Similar to the present results, Yang and Kang (35) previously found that quercetin and resveratrol treatment restored the levels of hepatic glucose metabolic enzymes, improved the antioxidant capacities and serum lipid profiles of STZ-induced diabetic rats. Co-treatment with quercetin and resveratrol exerted more pronounced effects against all deleterious symptoms of diabetic conditions in rats (35). Therefore, findings of the present study are consistent with previous observations that PILE possesses strong antioxidant activity, which may contribute to its prophylactic effect against organ dysfunction caused by prolonged chronic hyperglycemia.

Accumulating evidence suggested that the pathogenesis and progression of diabetic liver damage is due to the feedback mechanism between oxidative stress and inflammation $(7,24,36)$. Immune cells, including $\mathrm{T}$ cells, natural killer $\mathrm{T}$ cells and macrophages, are the first line of defense in the innate immune response, that impact the initial stages of diabetes-induced liver damage $(36,37)$. In particular, Kupffer cells, which are liver-resident macrophages, are critical in the regulation of the progression and resolution of tissue injury (37). Once oxidative stress occurs, Kupffer cells become activated, leading to tissue injury by stimulating the release of inflammatory cytokines, including IL-6 and TNF- $\alpha$ (8). The role of IL- 6 in metabolic regulation is rather complex. Previous observations suggested that IL-6-deficient mice (IL-6 ${ }^{--}$) developed mature-onset diabetes with liver inflammation and hepatosteatosis (38), indicating a protective role for IL-6 on hepatocytes. However, under inflammatory conditions, IL-6 can be excessively excreted by Kupffer cells, which can be regarded as a biomarker of acute liver damage (39). Under the experimental conditions considered in the present study, the expression of IL- 6 and TNF- $\alpha$ were found to be significantly increased in the livers of untreated STZ mice, whilst PILE 100 significantly attenuated the levels of pro-inflammatory cytokines, which was reflected by a reduction in liver inflammation. In the liver, IL-6 is not only important for infection defense but also crucial for hepatocyte homeostasis and regeneration $(37,40)$. Previous studies show that following hepatectomy or liver damage, gut-derived factors such as lipopolysaccharides activate the Kupffer cells, resulting in TNF- $\alpha$-dependent secretion of IL-6, consequently promoting liver regeneration $(37,40)$. Although liver regeneration was not investigated in the present 
study, PILE-induced amelioration of IL-6 and TNF- $\alpha$ in STZ mice could potentially provide favorable systemic conditions for hepatocyte recovery from diabetes-associated cellular injury, thereby restoring normal function.

The transcription factor NF- $\kappa B$ p 65 is activated by oxidative stress and the upregulation of IL- 6 and TNF- $\alpha$ (25). Activated NFkB p65 then activates downstream targets such as TGF $\beta 1$ and PKC, which further exacerbate liver toxicity. TGF- $\beta 1$ has long been regarded as a profibrogenic, anti-inflammatory and immunosuppressive mediator $(9,26,37)$. In the present study, TGF $\beta 1$ and PKC levels were significantly increased following STZ treatment under hyperglycemic conditions. By contrast, strong inhibition of TGF $\beta 1$ and PKC was noted in PILE 100-treated mice compared with untreated STZ mice, which was more pronounced when treatment was extended to 8 weeks. These findings suggested that PILE attenuates the inflammatory response by inhibiting the NFKB p65/TGF $\beta 1 / \mathrm{PKC}$ pathway. In addition, TNF- $\alpha$ was previously shown to be involved in apoptotic regulation through a classical cascade pathway, resulting in hepatocellular death (6). In the present study, the administration of PILE downregulated the expression of cleaved caspase- 9 and caspase-3, whilst significantly upregulating Bcl-2. These results suggested that PILE is able to counteract cell death in the diabetic liver. Nevertheless, further studies are required to clarify the detailed mechanism of PILE treatment and its inhibitory effects on oxidant and inflammatory markers.

To the best of our knowledge, the results of the present study demonstrated for the first time that PILE attenuated diabetic liver damage by modulating oxidative stress and inflammatory responses via the inhibition of TNF- $\alpha$, IL-6, NF- $\kappa B$ p65, TGF- $\beta 1$ and PKC in STZ mice (Fig. 5E). This may lead to a reduction in apoptosis and simultaneously improve cellular survival in the liver, thereby preserving hepatocyte architecture. These findings validated the ethanomedicinal applications of PILE for the management of diabetic liver damage.

\section{Acknowledgements}

The authors also would like to thank Associate Professor Dr Kitichate Sridith (Department of Biology, Faculty of Science, Prince of Songkla University, Hat Yai, Thailand) for kindly authenticating the plant material for this study.

\section{Funding}

This work was supported by research grants from Prince of Songkla University (grant nos. SCI601252S and SCI600505N) and the Thailand Research Fund (grant no. MRG6080028).

\section{Availability of data and materials}

The datasets used and/or analyzed during the present study are available from the corresponding author on reasonable request.

\section{Authors' contributions}

$\mathrm{JN}$ curated, performed the staining and western blot analysis, analyzed the data, acquired the funding and drafted the manu- script. AN and AP conceptualized the study and methodology, prepared and analyzed the plant materials, acquired the funding and reviewed and edited the manuscript. All authors read and approved the final version of this manuscript.

\section{Ethics approval and consent to participate}

The experimental protocols described in the present study were approved and guided by the Institutional Animal Care and Use Committee of Prince of Songkla University (Hat Yai, Thailand; approval no. MOE 0521.11/124).

\section{Patient consent for publication}

Not applicable.

\section{Competing interests}

The authors declare that they have no competing interests.

\section{References}

1. Danaei G, Finucane MM, Lin JK, Singh GM, Paciorek CJ, Cowan MJ, Farzadfar F, Stevens GA, Lim SS, Riley LM, et al: National, regional, and global trends in systolic blood pressure since 1980: Systematic analysis of health examination surveys and epidemiological studies with 786 country-years and $5 \cdot 4$ million participants. Lancet 377: 568-577, 2011.

2. Lee Yh, Cho Y, Lee BW, Park CY, Lee DH, Cha BS and Rhee EJ: Nonalcoholic fatty liver disease in diabetes. Part I: Epidemiology and diagnosis. Diabetes Metab J 43: 31-45, 2019.

3. Adams LA, Harmsen S, St Sauver JL, Charatcharoenwitthaya P, Enders FB, Therneau T and Angulo P: Nonalcoholic fatty liver disease increases risk of death among patients with diabetes: A community-based cohort study. Am J Gastroenterol 105: $1567-1573,2010$.

4. Hazlehurst JM, Woods C, Marjot T, Cobbold JF and Tomlinson JW: Non-alcoholic fatty liver disease and diabetes. Metabolism 65: 1096-1108, 2016.

5. Garcia-Compean D,Jacquez-Quintana JO,Gonzalez-GonzalezJA and Maldonado-Garza H: Liver cirrhosis and diabetes: Risk factors, pathophysiology, clinical implications and management. World J of Gastroenterol 15: 280-288, 2009.

6. Ingaramo PI, Ronco MT, Francés DE, Monti JA, Pisani GB, Ceballos MP, Galleano M, Carrillo MC and Carnovale CE: Tumor necrosis factor alpha pathways develops liver apoptosis in type 1 diabetes mellitus. Mol Immunol 48: 1397-1407, 2011.

7. Pan L, Weng H, Li H, Liu Z, Xu Y, Zhou C, Lu X, Su X, Zhang Y and Chen D: Therapeutic effects of bupleurum polysaccharides in streptozotocin induced diabetic mice. PLoS One 10: e0133212, 2015.

8. Schmidt-Arras D and Rose-John S: IL-6 pathway in the liver: From physiopathology to therapy. J Hepatol 64: 1403-1415, 2016.

9. Liaskou E, Zimmermann HW, Li KK, Oo YH, Suresh S, Stamataki Z, Qureshi O, Lalor PF, Shaw J, Syn WK, et al: Monocyte subsets in human liver disease show distinct phenoty pic and functional characteristics. Hepatology 57: 385-398, 2013.

10. Bilal HM, Riaz F, Munir K, Saqib A and Sarwar MR: Histological changes in the liver of diabetic rats: A review of pathogenesis of nonalcoholic fatty liver disease in type 1 diabetes mellitus. Cogent Med 3: 1, 2016.

11. Vongsak B, Kongkiatpaiboon S, Jaisamut S and Konsap K: Comparison of active constituents, antioxidant capacity, and $\alpha$-glucosidase inhibition in Pluchea indica leaf extracts at different maturity stages. Food Biosci 25: 68-73, 2018.

12. Noridayu AR, Hii YF, Faridah A, Khozirah S and Lajis N: Antioxidant and antiacetylcholinesterase activities of Pluchea indica Less. Int Food Res J 18: 925-929, 2011.

13. Buapool D, Mongkol N, Chantimal J, Roytrakul S, Srisook E and Srisook K: Molecular mechanism of anti-inflammatory activity of Pluchea indica leaves in macrophages RAW 264.7 and its action in animal models ofinflammation. J Ethnopharmacol 146: 495-504, 2013. 
14. Roslida AH, Erazuliana AK and Zuraini A: Anti-inflammatory and antinociceptive activities of the ethanolic extract of Pluchea indica $(\mathrm{L})$ less leaf. Pharmacologyonline 2: 349-360, 2008.

15. Widyawati PS, Budianta TDW, Gunawan DI and Wongso RS: Evaluation antidiabetic activity of various leaf extracts of Pluchea indica less. Int J Pharmacogn Phytochem Res 7: 597-603, 2015.

16. Pramanik KC, Bhattacharya P, Biswas R, Bandyopadhyay D, Mishra M and Chatterjee TK: Hypoglycemic and antihyperglycemic activity of leaf extract of Pluchea indica Less. Orient Pharm Exp Med 6: 232-236, 2006.

17. Nopparat J, Nualla-Ong A and Phongdara A: Ethanolic extracts of Pluchea indica (L.) leaf pretreatment attenuates cytokine-induced $\beta$-cell apoptosis in multiple low-dose streptozotocin-induced diabetic mice. PLoS One 14: e0212133, 2019

18. Landin-Olsson M: Latent autoimmune diabetes in adults. Ann NY Acad Sci 958: 112-116, 2002.

19. Eleazu CO, Eleazu KC, Chukwuma S and Essien UN: Review of the mechanism of cell death resulting from streptozotocin challenge in experimental animals, its practical use and potential risk to humans. J Diabetes Metab Disord 12: 60, 2013.

20. Tesch GH and Allen TJ: Rodent models of streptozotocin-induced diabetic nephropathy. Nephrology 12: 261-266, 2007.

21. Furman BL: Streptozotocin-induced diabetic models in mice and tats. Curr Protoc Pharmacol 70: 1-20, 2015.

22. Yu W, Zha W, Guo S, Cheng H, Wu J and Liu C: Flos puerariae extract prevents myocardial apoptosis via attenuation oxidative stress in streptozotocin-induced diabetic mice. PLoS One 9: e98044, 2014.

23. Gallol LE and Mohamed FH: Immunomorphometric variations of sustentacular cells of the male viscacha adrenal medulla during the annual reproductive cycle. Effects of androgens and melatonin. Acta Histochem 120: 363-372, 2018.

24. Palsamy P, Sivakumar S and Subramanian S: Resveratrol attenuates hyperglycemia-mediated oxidative stress, proinflammatory cytokines and protects hepatocytes ultrastructure in streptozotocin-nicotinamide-induced experimental diabetic rats. Chem Biol Interact 186: 200-210, 2010.

25. Manna P, Das J, Ghosh J and Sil PC: Contribution of type 1 diabetes to rat liver dysfunction and cellular damage via activation of NOS, PARP, IkappaB alpha/NF-kappaB, MAPKs, and mitochondria-dependent pathways: Prophylactic role of arjunolic acid. Free Radic Biol Med 48: 1465-1484, 2010.

26. Dongiovanni P, Anstee QM and Valenti L: Genetic predisposition in NAFLD and NASH: impact on severity of liver disease and response to treatment. Curr Pharm Des 19: 5219-5238, 2013.

27. Sirichaiwetchakoon K, Lowe GM, Thumanu K and Eumkeb G: The Effect of Pluchea indica (L.) Less. Tea on Adipogenesis in 3T3-L1 Adipocytes and Lipase Activity. Evid Based Complement Alternat Med 2018: 4108787, 2018.

28. Ruan J, Li Z, Yan J, Huang P, Yu H, Han L, Zhang Y and Wang T: Bioactive constituents from the aerial parts of Pluchea indica less. Molecules 23: pii: E2104, 2018.
29. Mukhopadhyay P and Prajapati AK: Quercetin in anti-diabetic research and strategies for improved quercetin bioavailability using polymer-based carriers-a review. RSC Advances 5: 97547-97562, 2015.

30. Jeong SM, Kang MJ, Choi HN, Kim JH, and Kim JI: Quercetin ameliorates hyperglycemia and dyslipidemia and improves antioxidant status in type 2 diabetic db/db mice. Nutr Res Pract 6: 201-207, 2012.

31. Yazgan UC, Tasdemir E, Bilgin HM, Obay BD, Sermet A and Elbey B: Comparison of the anti-diabetic effects of resveratrol, gliclazide and losartan in streptozotocin-induced experimental diabetes. Arch Physiol Biochem 121: 157-161, 2015.

32. Arsiningtyas IS, Gunawan-Puteri MD, Kato E and Kawabata J: Identification of $\alpha$-glucosidase inhibitors from the leaves of Pluchea indica (L.) Less., a traditional Indonesian herb: Promotion of natural product use. Nat Prod Res 28: 1350-1353, 2014.

33. Ohno T, Horio F, Tanaka S, Terada M, Namikawa T and Kitoh J: Fatty liver and hyperlipidemia in IDDM (insulin-dependent diabetes mellitus) of streptozotocin-treated shrews. Life Sci 66: 125-131, 2002.

34. Chatrath H, Vuppalanchi R and Chalasani N: Dyslipidemia in patients with nonalcoholic fatty liver disease. Semin Liver Dis 32: 22-29, 2012.

35. Yang DK and Kang HS: Anti-diabetic effect of cotreatment with quercetin and resveratrol in streptozotocin-induced diabetic rats. Biomol Ther 26:130-138, 2018.

36. Palsamy P and Subramanian S: Ameliorative potential of resveratrol on proinflammatory cytokines, hyperglycemia mediated oxidative stress, and pancreatic beta-cell dysfunction in streptozotocin-nicotinamide-induced diabetic rats. J Cell Physiol 224: 423-432, 2010.

37. Zhan YT and An W: Roles of liver innate immune cells in nonalcoholic fatty liver disease. World J Gastroenterol 16:4652-4660, 2010.

38. Wallenius V, Wallenius K, Ahrén B, Rudling M, Carlsten H, Dickson SL, Ohlsson C and Jansson JO: Interleukin-6-deficient mice develop mature-onset obesity. Nat Med 8: 75-79, 2002.

39. Matthews VB, Allen TL, Risis S, Chan MHS, Henstridge DC, Watson N, Zaffino LA, Babb JR, Boon J, Meikle PJ, et al: Interleukin-6-deficient mice develop hepatic inflammation and systemic insulin resistance. Diabetologia 53: 2431-2441, 2010.

40. Kolios G, Valatas V and Kouroumalis E: Role of Kupffer cells in the pathogenesis of liver disease. World J Gastroenterol 12: 7413-7420, 2006

c) (i) $\ominus$ This work is licensed under a Creative Commons

Attribution-NonCommercial-NoDerivatives 4.0 International (CC BY-NC-ND 4.0) License. 